\title{
Updated national emission inventory and comparison with the Emissions Database for Global Atmospheric Research (EDGAR): case of Lebanon
}

\author{
Anwar Al Shami ${ }^{1}$ - Elissar Al Aawar ${ }^{2}$ - Abdelkader Baayoun ${ }^{2}$. Najat A. Saliba ${ }^{3}$. Jonilda Kushta ${ }^{4}$. \\ Theodoros Christoudias ${ }^{4}$. Issam Lakkis ${ }^{2}$ (D)
}

Received: 5 May 2021 / Accepted: 12 November 2021 / Published online: 8 January 2022

(C) The Author(s) 2022

\begin{abstract}
Physically based computational modeling is an effective tool for estimating and predicting the spatial distribution of pollutant concentrations in complex environments. A detailed and up-to-date emission inventory is one of the most important components of atmospheric modeling and a prerequisite for achieving high model performance. Lebanon lacks an accurate inventory of anthropogenic emission fluxes. In the absence of a clear emission standard and standardized activity datasets in Lebanon, this work serves to fill this gap by presenting the first national effort to develop a national emission inventory by exhaustively quantifying detailed multisector, multi-species pollutant emissions in Lebanon for atmospheric pollutants that are internationally monitored and regulated as relevant to air quality. Following the classification of the Emissions Database for Global Atmospheric Research (EDGAR), we present the methodology followed for each subsector based on its characteristics and types of fuels consumed. The estimated emissions encompass gaseous species $\left(\mathrm{CO}, \mathrm{NO}_{x}, \mathrm{SO}_{2}\right)$, and particulate matter $\left(\mathrm{PM}_{2.5}\right.$ and $\left.\mathrm{PM}_{10}\right)$. We compare totals per sector obtained from the newly developed national inventory with the international EDGAR inventory and previously published emission inventories for the country for base year 2010 presenting current discrepancies and analyzing their causes. The observed discrepancies highlight the fact that emission inventories, especially for data-scarce settings, are highly sensitive to the activity data and their underlying assumptions, and to the methodology used to estimate the emissions.
\end{abstract}

Keywords National inventory $\cdot$ Lebanon $\cdot$ EDGAR inventory $\cdot$ Emissions standard

\section{Introduction}

Poor governments are currently trying to improve air quality by imposing national policies to control pollution sources (Font and Fuller 2016; Jin et al. 2016; Li and Chen 2018). These policies are usually based on the assessment of emission scenarios with the air quality is a severe issue in many countries worldwide affecting public health and ecosystems. In order to effectively manage and mitigate these effects, use of air quality models that investigate the impact of reducing emission rates of the

Responsible Editor: Gerhard Lammel

Issam Lakkis

i101@aub.edu.lb

Extended author information available on the last page of the article. different sources, changing their operating schedule, their technological adaptation or even their spatial distribution. The two main inputs to these models are the driving meteorological conditions, and the inventory of pollutant emissions (Agarwal and Haritash 2014). Forecasting and reanalyzing the meteorology has improved over the years (Yan et al. 2019; Zhao et al. 2016; Ghadban et al. 2020), and having a detailed spatio-temporal emission inventory remains the outstanding major challenge (Bang and Khue 2019; Georgiou et al. 2019). Because they are essential to air quality studies and policy making, global and local emission inventories have been the subject of many studies. Several modules were established and constantly improved to process and compute atmospheric emissions from different sources. Many approaches were proposed to deal with different types of sources and pollutants with varying spatial and temporal resolutions. These efforts aim to build an efficient emissions database with acceptable 
levels of details for further studies while employing the advances in the meteorological analyses (Guevara et al. 2019, 2020; Grythe et al. 2019). Such modeled estimations can always be verified for precision and accuracy by comparing with measurements and other verified models. This process enables filling gaps and building reliable emission inventories. In addition, monitoring trends of emissions spatially and temporally can serve as a basis for policy making and modification along with subsequent actions that follow (Fameli and Assimakopoulos 2016).

For countries exhibiting scarcity in emissions data, global emission inventories have traditionally been an alternative solution (Madrazo et al. 2018). A well-known and widely used global emission inventory is the Emissions Database for Global Atmospheric Research (EDGAR) developed by the Joint Research Center (JRC). EDGAR provides gridded annual anthropogenic emissions datasets for the period of 1970-2012 on a spatial resolution of $0.1^{\circ} \times 0.1^{\circ}$ (Edgar 2019b). The activity data, i.e., fuel consumption for the different sectors is based on international statistics for each country produced by the International Energy Agency (IEA) (Data and statistics 2019). The emission factors utilized in EDGAR datasets are country specific for each sector (Janssens-Maenhout et al. 2015).

EDGAR has been used as a reference to ensure the development of control measures in order to mitigate the effects of certain high emissions (Salameh et al. 2016). It also served as an input to air quality modeling software such as WRF-Polyphemus and WRF-CHEM (Abdallah et al. 2016, 2018; Kedia et al. 2019; Upadhyay et al. 2019). In addition, EDGAR was considered as a validation basis for studies related to emissions of different pollutants using various modeling approaches (Dentener et al. 2002; Bergamaschi et al. 2010). However, a comparison between EDGAR and national developed emission inventories showed that even though EDGAR can be applicable for continental-scale modeling, it is not recommended for regional to local air quality simulations, and a more complete and up-to-date national emission inventory should be used instead (Madrazo et al. 2018; Puliafito et al. 2017; van Amstel et al. 1999; Hristov et al. 2017; Liousse et al. 2019; Georgiou et al. 2020; Kushta et al. 2019).

Lebanon, a small country located on the Eastern coast of the Mediterranean Sea, is considered as a hotspot in the Mediterranean basin and Middle East region in terms of air pollution. Lebanon suffers from an unsustainable road transport sector (Daher et al. 2013; Haddad et al. 2018), unmaintained power plants (Ghanem 2018), and an unregulated private diesel generator sector (Bouri and El Assad 2016; Ghanem 2018; Shihadeh et al. 2018). Therefore, there is a crucial need to conduct accurate air quality modeling studies over the country and in the region (i.e., with reduced uncertainties) based on a refined emission inventory in order to study scenarios and to come up with effective policies to mitigate air pollution impacts. However, the development of national emission inventory is a difficult work to complete since the necessary data such as activity profiles, energy consumption, and fleet characteristics are not always available, even more challenging in a data-scarce environment such as Lebanon.

A complete national emission inventory was first developed for Lebanon for the base year of 2010 by Waked et al. (2012). Later on, a collaboration between the American University of Beirut (AUB) and the Ministry of Environment (MoE) estimated emissions trends for the two key sources of air pollution in Lebanon, diesel generators and light duty vehicles (Baayoun et al. 2019). The study presented a more robust methodology to estimate the emissions than the one adopted by Waked et al. In the current paper, we present a national emission inventory for Lebanon for the base year of 2010 comprising a combination and refinement of the work done by AUB and MoE (Baayoun et al. 2019) and by Waked et al. (2012). We compare, contrast and discuss discrepancies between the newly developed inventory and EDGAR based on total emissions. The base year 2010 was selected because it allows for direct and fair comparison with the previous work done by Waked et al. (2012) which presented an emission inventory for the same year, and with the EDGAR emissions database, which also corresponds to the year 2010. Using the same base year enables us to uniquely and novelly identify discrepancies and for the first time estimate the uncertainties systematically for all pollutants. Our study is further motivated by the outcomes of Salameh et al. (2016) that there is strong evidence that global inventories (including EDGAR) underestimate the emissions by up to a factor of 10 for the transportation sector in Lebanon, and an assessment of anthropogenic emission inventories was deemed necessary as these emissions could be much higher than expected at least from the road transport sector. Emission estimates from light duty vehicles benefit from the use of a more robust methodology than the one adopted by Waked et al. (2012), including emission trends for over a decade, as outlined in Baayoun et al. (2019) for light duty vehicles. For the first time, this work accounts for the emissions of heavy duty vehicles separately leading to a significant revision of previous values in this sector. Also, this study improves markedly upon the previous work by the American University of Beirut (Baayoun et al. 2019) and the Ministry of Environment of Lebanon. Prescribed best practices following EEA standards and recommendations and current state-of-the-art methodology is applied.

This work represents the first national effort in quantifying detailed multisector, multi-species pollutant emissions for Lebanon. The aim is to produce an accurate emission inventory which serves as the backbone of model-based 
pollution assessment and forecasting, air quality management, policy making, decision making and evaluation of mitigation strategies. This is achieved by following the European Environmental Agency methods, recommendations and practices and using the climate change report by the Ministry of Environment as the main source of activity data (Min 2017; Ministry of Environment 2015a; Ipcc guidelines 2006a). The intercomparison between the three different inventories uncovers and provides an estimate of the associated uncertainties.

\section{Data and methods}

\section{National inventory}

A national emission inventory, including breakdown by sector, was developed for Lebanon. The categorization of the sectors (as shown in Table 1) follows the EDGAR classification and allows for direct intercomparison. We limit the pollutants reported in this study to the ones reported in common by EDGAR and Waked et al. (2012) for the sake of comparison. In the absence of much of the activity data for other pollutants, it was not possible to estimate their emissions. Of the criteria pollutants $\left(\mathrm{SO}_{x}\right.$, $\mathrm{NO}_{x}, \mathrm{CO}, \mathrm{PM}, \mathrm{Pb}$, and $\mathrm{O}_{3}$ ), we did not include $\mathrm{O}_{3}$ and $\mathrm{Pb}$. Estimating $\mathrm{O}_{3}$ is not meaningful without accounting for its secondary reactions in the atmosphere. As for lead, its emission factors are not available for key sectors. Therefore, our inventory speciation includes emissions of carbon monoxide $(\mathrm{CO})$, nitrogen oxides $\left(\mathrm{NO}_{x}\right)$, sulfur dioxide $\left(\mathrm{SO}_{2}\right), \mathrm{PM}_{2.5}$ and $\mathrm{PM}_{10}$. Emissions per species are estimated using the following formula:

$$
\text { Emission }=\text { activity rate } \times \text { emission factor }
$$

Emission factors used are presented in details in the Supplementary material in Tables S.1 to S.8.

\section{Air transport sector}

The aviation sector is divided into two categories: domestic aviation and international aviation. Domestic aviation includes flights that depart and arrive at airports within Lebanon and is limited to the operation of five small propeller-type aircraft, used only for training at Beirut International Airport. They usually operate on jet gasoline with an average annual consumption around 3 ktonnes (kt), i.e., $3.30 \mathrm{kt}$ in 2010 (MoE based on personal communication with Cap. Said El Hage in Beirut Airport). The bulk of this sector is represented in the international flights that depart from or arrive at different countries. However, these should be disregarded for the purpose of constructing a national emission inventory (Unf 2019; Aviation emissions and the paris agreement 2016). The air transport sector emissions

Table 1 Sectors categorization and type of activity rate for each sector

\begin{tabular}{|c|c|c|c|c|}
\hline Sector & $\begin{array}{l}\text { Sub } \\
\text { sectors }\end{array}$ & $\begin{array}{l}\text { Activity } \\
\text { rate }\end{array}$ & $\begin{array}{l}\text { Emission } \\
\text { factors }\end{array}$ & Reference \\
\hline Air transport & $\begin{array}{l}\text { Domestic } \\
\text { aviation }\end{array}$ & $\begin{array}{l}\text { Energy produced/ } \\
\text { fuel consumption }\end{array}$ & $\begin{array}{l}\text { IPCC \& } \\
\text { EMEP-EEA }\end{array}$ & This paper \\
\hline Ships transport & Domestic navigation & $\begin{array}{l}\text { Energy produced/ } \\
\text { fuel consumption }\end{array}$ & $\begin{array}{l}\text { IPCC \& } \\
\text { EMEP-EEA }\end{array}$ & This paper \\
\hline Energy & $\begin{array}{l}\text { Power plants } \\
\text { Diesel generators }\end{array}$ & $\begin{array}{l}\text { Energy produced } \\
\text { Fuel consumption }\end{array}$ & $\begin{array}{l}\text { EMEP-EEA } \\
\text { EMEP-EEA }\end{array}$ & $\begin{array}{l}\text { This paper } \\
\text { Baayoun et al. (2019) }\end{array}$ \\
\hline Industry & Industrial sites & Fuel consumption & EMEP-EEA & Waked et al. (2012) \\
\hline Road transport & $\begin{array}{l}\text { Light duty } \\
\text { vehicles (LDVs) }\end{array}$ & $\begin{array}{l}\text { Average traveled } \\
\text { distance }\end{array}$ & Diesel Net & Baayoun et al. (2019) \\
\hline & $\begin{array}{l}\text { Heavy duty } \\
\text { vehicles (HDVs) }\end{array}$ & $\begin{array}{l}\text { Average traveled } \\
\text { distance/fuel } \\
\text { consumption/energy } \\
\text { produced }\end{array}$ & $\begin{array}{l}\text { Diesel Net/ } \\
\text { EMEP-EEA/ } \\
\text { US EPA }\end{array}$ & This paper \\
\hline Residential & $\begin{array}{l}\text { Space heating } \\
\text { Cooking } \\
\text { Agriculture machinery } \\
\text { Solid waste }\end{array}$ & $\begin{array}{l}\text { Fuel consumption } \\
\text { Fuel consumption } \\
\text { Fuel consumption } \\
\text { Fuel consumption }\end{array}$ & $\begin{array}{l}\text { EMEP-EEA } \\
\text { EMEP-EEA } \\
\text { EMEP-EEA } \\
\text { EMEP-EEA }\end{array}$ & $\begin{array}{l}\text { This paper } \\
\text { This paper } \\
\text { Waked et al. (2012) } \\
\text { Waked et al. (2012) }\end{array}$ \\
\hline
\end{tabular}

IPCC, Intergovernmental Panel on Climate Change; EMEP-EEA, European Monitoring and Evaluation Programme-European Environmental Agency; US EPA, United States Environmental Protection Agency 
were estimated based on annual fuel consumption. Average Tier 1 emission factors for $\mathrm{CO}, \mathrm{SO}_{2}$ and $\mathrm{NO}_{x}$ for jet gasoline were used based on the IPCC 2006 guidelines (Ipcc guidelines 2006b). The emission factor of PM was retrieved from the EMEP-EEA guidelines (Finstad et al. 2001, 2002). The emission factors obtained from IPCC are in terms of the energy provided by the fuel consumed. As detailed in Table 2, to calculate this energy value, the country-specific net calorific value NCV (provided by the Ministry of Energy and Water, MoEW) of the fuel was multiplied by the annual fuel consumption, which acts as the activity rate. The NCV value used for jet gasoline is $43.50 \mathrm{TJ} / \mathrm{kt}$. Regarding PM (this refers to both $P M_{2.5}$ and $P M_{10}$ here and elsewhere in this document), the emission factors obtained from EEA are based on the fuel consumption and thus the activity rate used for PM is the annual fuel consumption.

\section{Ships transport sector}

The covered activities related to shipping include only those related to domestic navigation. These are mainly restricted to fishing boats whose power source is diesel oil (Ministry of Environment 2015b). As detailed in Table 3, sectoral consumption of diesel serving as the activity rate for 2010 was $51.6 \mathrm{kt}$ (Ministry of Environment 2015a). Similarly, as in the air transport section, the Average Tier 1 emission factors for the studied pollutants were retrieved and used in the Tier 1 default approach (EUR 2016b; Eur 2019b).

\section{Energy sector}

Power plants Annual total energy production data for the seven thermal power plants installed in Lebanon (namely Zouk, Jieh, Hrayche, Deir Ammar, Zahrani, Baalbeck and Tyre) was provided by Ministry of Environment (2015a) as shown in Table 4.

Power plant emissions were estimated using Eq. 1 where the activity rate is the total annual energy produced by the power plants. Since most of these power plants are unmaintained, upper Tier 1 emission factors for fossil fuel power plants were used according to the EMEP/EEA air pollutant emission inventory guidebook (EUR 2016a). The computed activity rates are shown in Section 5.
Diesel generators Baayoun et al. (2019) estimated the annual emissions from diesel generators in Lebanon spanning the period 2009-2016. Baayoun et al. (2019) The total amount of fuel consumed by diesel generators in Lebanon was derived from two sources: the first was the total amount of fuel imported and reported by the Central Administration of Statistics (CAS) (Cas statistical yearbook 2016) on behalf of the MoEW and the second was the distribution by sector as stated by one of the major oil and gas companies, Issa Petrol Trade Energy Center (IPTEC) (MoE, 2017; shared source data). Table 5 lists the energy sector categories and type of activity rate for each pollutant. Diesel generator emissions were calculated according to the EMEP/EEA air pollutant emission inventory guidebook using the Tier 2 methodology for reciprocating engine applications and the emission factors found in the small combustion data of the guidebook (EUR 2016b).

\section{Industry}

The emissions of this sector were estimated by Waked et al. (2012) based on the total fuel consumed by the different Lebanese industries. These quantities are reported based on the CAS, MoEW statistics of industrial fuel imports for 2010 (Cas statistical yearbook 2016). The activity rate is equivalent to $199.724 \mathrm{kt}$ of fuel oil. This quantity is then associated with their relative Tier 2 technology specific emission factors (Eur 2019a).

\section{Road transport}

The estimation of the traffic emissions takes into account the characteristics of the vehicle fleet (the model type, model year, fuel type used, origin, number of cylinders, energy output of the motor, and the year of circulation). The database for these characteristics was obtained from the national vehicle registry (Min 2017) for the base year 2010. Vehicles were classified into two categories: light duty vehicles (LDVs) and heavy duty vehicles (HDVs). Any vehicle with a weight less than $3,500 \mathrm{~kg}$ is referred to an LDV; otherwise, it is considered as an HDV.

Light duty vehicles Analyzing the fleet distribution, LDVs constitute the majority of the circulating vehicles for each
Table 2 Sector categorization and type of activity rate for each pollutant in the air transport sector

\begin{tabular}{lllll}
\hline & Activity type & Activity value & Pollutants & Emission factors \\
\hline Domestic aviation & Fuel consumption & $3.30 \mathrm{kt}$ & $\mathrm{PM}$ & EMEP/EEA (Tier 1) \\
& Energy produced & $143.55 \mathrm{TJ}$ & $\mathrm{CO}, \mathrm{SO}_{2}, \mathrm{NO}_{x}$ & IPCC (Tier 1) \\
\hline
\end{tabular}

IPCC, Intergovernmental Panel on Climate Change; EMEP-EEA, European Monitoring and Evaluation Programme-European Environmental Agency 
Table 3 Sector categorization and type of activity rate for each pollutant in the ships transport sector (EMEP-EEA, European Monitoring and Evaluation Programme-European Environmental Agency)

\begin{tabular}{llll}
\hline Activity type & Activity value & Pollutants & Emission factor \\
\hline Fuel consumption & $51.6 \mathrm{kt}$ & $\mathrm{CO}, \mathrm{SO}_{2}, \mathrm{NO}_{x}, \mathrm{PM}$ & EMEP/EEA (Tier 1) \\
Energy produced & $1068.6 \mathrm{TJ}$ & $\mathrm{CO}, \mathrm{SO}_{2}, \mathrm{NO}_{x}$ & $\mathrm{IPCC}(\mathrm{Tier} 1)$ \\
\hline
\end{tabular}

year at around $90 \%$ of the total fleet during 2010. The LDVs were further classified based on the origin of each vehicle into three groups: European origin (EU), US origin (US) and Japanese origin (Jap) with Korean origin vehicles being included in the Japanese ones as they follow the Japanese standards. The activity rate used in retrieving the emissions of this sector is the total annual traveled distance of all LDVs. The average traveled distance by vehicle origin was obtained using vehicle fuel efficiencies and national fuel consumption (Baayoun et al. 2019).

In addition, average Tier 2 emission factors were obtained for all pollutants, except $\mathrm{SO}_{2}$, based on the type of fuel consumed (gasoline or diesel) according to the three groups of different origins of LDVs based on the categorization of Dieselnet (2019). The $\mathrm{SO}_{2}$ emission factor was calculated based only on the sulfur content of the fuel consumed, equivalent to Tier 1 emissions related to annual fuel consumption.

$E_{\mathrm{SO}_{2}}=k_{s, m} \times F C$

where $\mathrm{E}_{\mathrm{SO} 2}=$ emission of sulfur dioxide (in $\mathrm{Gg}$ ), $\mathrm{k}_{s, m}=$ sulfur mass content in fuel $\mathrm{m}$ (in $\mathrm{Gg}$ / tons of fuel), and $\mathrm{FC}=$ fuel consumption (in tons). Activity rates are summarized in Table 7.

Heavy duty vehicles Similarly, the total fleet distribution was filtered to get the total HDVs circulating in 2010. These were also divided based on the origin of each vehicle into three groups: EU origin, US origin and Asian origin. Furthermore, each group was divided into two subgroups based on the type of fuel consumed (diesel or gasoline "Commercial Trucks" DieselNet 2019) as shown in Table 6.

Table 4 Annual total energy production from the seven thermal power plants installed in Lebanon

\begin{tabular}{lll}
\hline Power plant & Fuel type & Energy $(\mathrm{GWh})$ \\
\hline Zouk & Heavy fuel oil & 2398 \\
Jieh & Heavy fuel oil & 1509 \\
Hrayche & Heavy fuel oil & 282 \\
Deir Ammar & Diesel oil & 2895 \\
Zahrani & Diesel oil & 3130 \\
Baalbeck & Diesel oil & 201 \\
Tyre & Diesel oil & 336 \\
\hline
\end{tabular}

The emission factors for each subgroup were obtained as follows: average Tier 2 emission factors were used for all US origin HDVs (Reichle et al. 2015) and Asia Gasoline HDVs (Dieselnet 2019). The activity rate is the annual total traveled distance which is $50,000 \mathrm{~km} / \mathrm{vehicle}$ in case of diesel HDVs and $27,250 \mathrm{~km} /$ vehicle in case of gasoline HDVs. These traveled distances are obtained using the ForFITS (For Future Inland Transport Systems) model which uses transport data provided by national and international transport agencies. Data for Lebanon was obtained using the model for countries with similar mobility characteristics (UNECE 2011). As for EU origin vehicles, average Tier 1 emission factors were used to estimate their emissions based on the annual fuel consumption (EUR 2016b).

Since the activity rate for the HDVs is the traveled distance, the estimation of the annual fuel consumption was made using the average consumption of each fuel per unit of distance traveled. That is on average $240 \mathrm{~g} / \mathrm{km}$ for diesel HDVs and $100 \mathrm{~g} / \mathrm{km}$ for gasoline HDVs as per EMEP/EEA. For the last subgroup, the Asian origin diesel HDVs, emission factors are based on the total energy produced (Dieselnet 2019). The energy produced is obtained based on the motor specifications provided by the national fleet registry documents. All the above specification refer to emission factors for $\mathrm{CO}, \mathrm{NO}_{x}, \mathrm{PM}_{2.5}$ and $\mathrm{PM}_{10} . \mathrm{SO}_{2}$ emission factors are based on the sulfur content of the fuel consumed and are always referred to as Tier 1 emissions. Equation 2 was used to calculate the $\mathrm{SO}_{2}$ emission factors for European HDVs (EUR 2016b) and Eastern HDVs, as these generally followed EURO III standards in 2010 (Wang et al. 2014). US HDVs $\mathrm{SO}_{2}$ emission factors were obtained from DieselNet (Dieselnet 2019).

\section{Residential sector}

Space heating and cooking The major types of fuel used for heating in Lebanon are gasoil, liquefied petroleum gas (LPG), and wood. Since no accurate data on the share of LPG and wood quantity used in this sector are available for analysis (UNFCCC 2011), we only consider the emissions due to residential boilers relying on gasoil. Fuel consumption data of this latter was obtained from IPTEC (MoE, 2017). In total, 172,249 metric tons (MT) of gasoil were estimated to be used for space heating in 2010 . 
Table 5 Sector categorization and type of activity rate for each pollutant in the energy sector

\begin{tabular}{llllll}
\hline & Activity type & Activity value & Pollutants & Emission factor & Reference \\
\hline Power plants & & & & & \\
HFO & Energy produced & $2680 \mathrm{GWH}$ & $\mathrm{CO}, \mathrm{SO}_{2}, \mathrm{NO}_{x}, \mathrm{PM}$ & EMEP/EEA (Tier 1) & This paper \\
$\mathrm{HFO}-5$ & Energy produced & $1509 \mathrm{GWH}$ & $\mathrm{CO}, \mathrm{SO}_{2}, \mathrm{NO}_{x}, \mathrm{PM}$ & $\mathrm{EMEP} / \mathrm{EEA}$ (Tier 1) & This paper \\
Diesel oil & Energy produced & $6562 \mathrm{GWH}$ & $\mathrm{CO}, \mathrm{SO}_{2}, \mathrm{NO}_{x}, \mathrm{PM}$ & EMEP/EEA (Tier 1) & This paper \\
Diesel generators & Fuel consumption & & $\mathrm{CO}, \mathrm{SO}_{2}, \mathrm{NO}_{x}, \mathrm{PM}$ & EMEP/EEA (Tier 2) & Baayoun et al. (2019) \\
\hline
\end{tabular}

EMEP-EEA, European Monitoring and Evaluation Programme-European Environmental Agency

A net calorific value of $43.38 \mathrm{GJ} /$ tons was used for gasoil. Space heating emission factors were taken according to the EMEP/EEA air pollutant emission inventory guidebook using the Tier 2 methodology for small boiler (residential) applications (EUR 2016b). The commonly used cooking appliances in Lebanon are predominantly gas stoves. Fuel consumption data of LPG used by these cooking appliances was obtained from IPTEC (MoE, 2017). In total, 177,858 MT of LPG were used for cooking in 2010. Emission factors were taken according to EMEP/EEA air pollutant emission inventory guidebook using the Tier 2 methodology for stoves burning gas (EUR 2016b). The calorific value of $50 \mathrm{GJ} /$ tons was used for LPG.

Agriculture and solid waste Waked et al. estimated the emissions of this sector in an approach similar to that used in the industry sector (Waked et al. 2012) that is based on the total fuel consumed by the agriculture machinery and the relative masses of the different types of incinerated wastes for 2010. These quantities are then associated with their relative Tier 1 emission factors as advised by EMEP-EEA guidelines (EUR 2016b).

\section{EDGAR HTAP equivalents}

Yearly values by sector for 2010 were obtained from the HTAP_V2 inventory dataset compiled by EDGAR team (JRC) (Edgar 2019a). HTAP_V2 is a compilation of different regional gridded inventories including that of EPA for the USA, the EPA and Environment Canada (for Canada), the EMEP and Netherlands Organisation for Applied Scientific Research (TNO) for Europe, and the Model Intercomparison Study for Asia (MICS-Asia III) for

Table 6 Heavy duty vehicle (HDV) fleet classification per origin and fuel type (total numbers for 2010)

\begin{tabular}{llll}
\hline HDV & EU origin & US origin & Asian origin \\
\hline Diesel & 10,883 & 668 & 17,914 \\
Gasoline & 29,285 & 4,132 & 45,045 \\
\hline
\end{tabular}

China, India and other Asian countries, while the rest of the world emissions are complemented by EDGARv4.3 (Janssens-Maenhout et al. 2015). The HTAP emission inventory provides data as emission fluxes $\left(\mathrm{kg} / \mathrm{m}^{2} / \mathrm{s}\right)$. Yearly emissions were calculated and summed over Lebanon. The implied emission factors per sector used by EDGAR for Lebanon are given in Table 8.

\section{Results and discussion}

\section{Updated national inventory}

The total estimated emissions by source sector for the year 2010 for $\mathrm{CO}, \mathrm{NO}_{x}, \mathrm{SO}_{2}, \mathrm{PM}_{2.5}$ and $\mathrm{PM}_{10}$ are 115.37, 97.31, $63.82,8.15$ and $10.36 \mathrm{Gg}$ respectively. The contribution of each sector to the total emissions of each pollutant is shown in Fig. 1. We note that road transport is the major sector contributing to $\mathrm{CO}$ emissions with a percentage of $77.7 \%$. Most CO emissions within this sector are mainly due to the LDV subsector (only gasoline vehicles as per Lebanese regulations) which alone releases $57 \%$ of the total $\mathrm{CO}$ emissions. The second contributor is the HDV sector (mostly diesel vehicles) contributing around $31.7 \%$ of the total $\mathrm{CO}$ emissions. As for $\mathrm{NO}_{x}$ and $\mathrm{SO}_{2}$ emissions, the bulk of these pollutants originate from the energy sector. The energy sector emits $63.6 \%$ of total $\mathrm{NO}_{x}$ and diesel generators alone contribute $52.79 \mathrm{Gg}$ of $\mathrm{NO}_{x}$. Energy production also emits $61.6 \%$ of total $\mathrm{SO}_{2}$ where the major contribution of $36.62 \mathrm{Gg}$ is from the power plants subsector. The industry sector estimations indicate that this sector is the predominant major polluting source for $\mathrm{PM}_{2.5}$ and $\mathrm{PM}_{10}$ with percentages of $60.81 \%$ and $66.4 \%$ respectively. The residential sector was found to be a small contributor across all pollutants as the only sources that could be estimated (as per EDGAR sector categorization) given data availability were the solid waste and agricultural machinery subsectors. The Agriculture sector was not estimated due to the absence of data. Among all the covered sectors and subsectors, we notice that the LDVs and diesel generators subsectors are the major contributors to total emissions of all the 


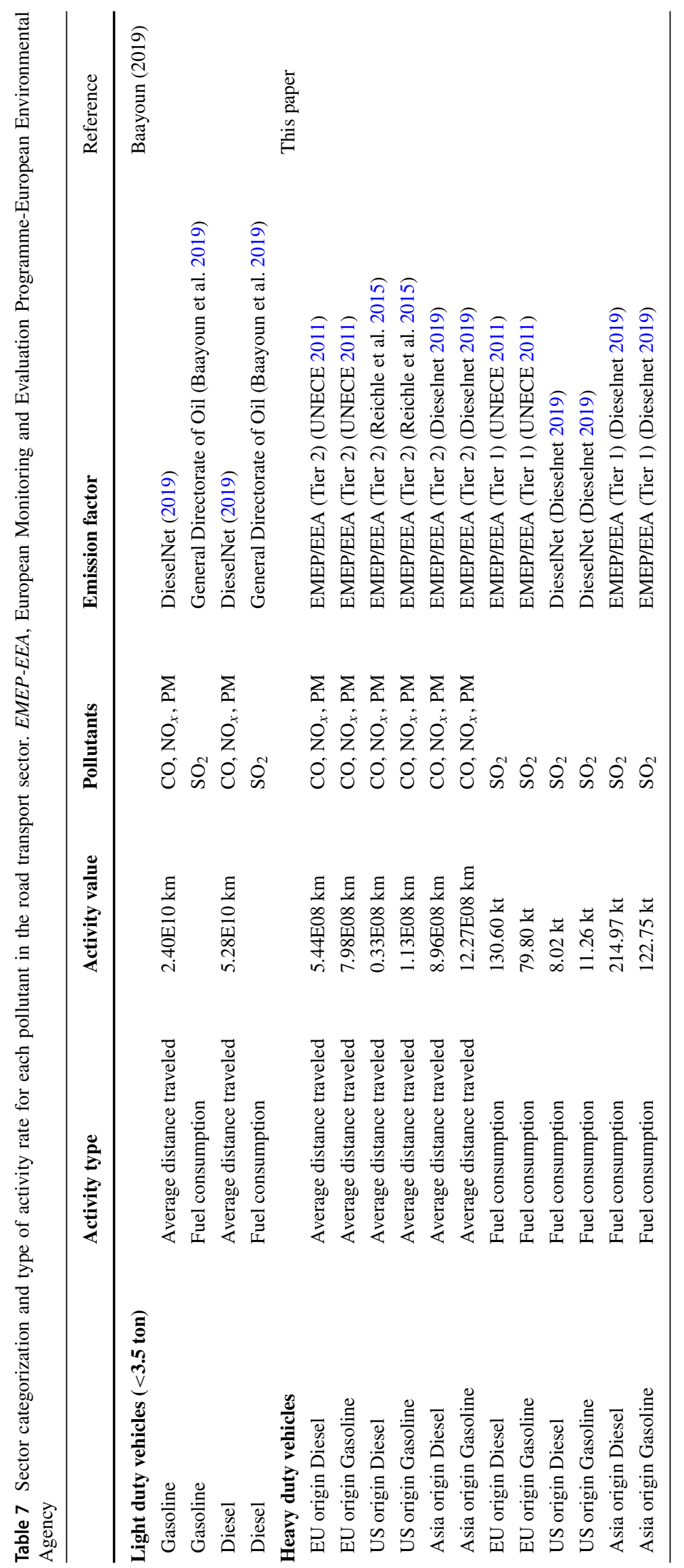


Table 8 Implied emission factors (in $\mathrm{g} / \mathrm{GJ}$ ) for Lebanon per species per source sector for 2010 from EDGAR HTAP_v2

\begin{tabular}{llllll}
\hline & $\mathrm{CO}$ & $\mathrm{NO}_{x}$ & $\mathrm{SO}_{2}$ & $\mathrm{PM}_{2.5}$ & $\mathrm{PM}_{10}$ \\
\hline Energy & 123.73 & 617.32 & 1113.72 & 6.65 & 8.95 \\
Industry & 52.88 & 150.50 & 691.88 & 56.08 & 76.48 \\
Residential & 345.56 & 67.89 & 155.84 & 26.82 & 50.23 \\
Transport & 1301.31 & 62.94 & 11.98 & 2.21 & 2.21 \\
\hline
\end{tabular}

studied pollutants with values of $66.89 \mathrm{Gg}$ and $66.13 \mathrm{Gg}$ respectively. That is due to the fact that the most dominant mode of transport in Lebanon is passenger cars with a ratio of 1 cars every 3 individuals (Chaaban et al. 2001). The random unregulated growth of the diesel power generation private sector is an emerging phenomenon in the Lebanese community caused by and compensating for the national electricity shortage.

\section{Comparison between different emission inventories for Lebanon}

The total of each studied sector is compared to that of the corresponding sector in EDGAR emission inventory. Our results were compared, specifically for the road sector, with those of Waked et al. (2012). The reason why that the comparison was made for this specific sector solely is that Waked et al. (2012) do not state the emissions of other subsectors, such as air and marine transport. In addition, the sub-divisions of the energy and residential sectors between the newly developed and Waked et al. inventory are different. Our inventory considers the diesel generators as a subsector of the energy sector, while Waked et al. considers it to be a part of the residential sector. The categorization we adopted is largely based on EDGAR classification. One notable difference is that while EDGAR accounts for emissions data on international activities in the air and marine transport sectors, we are dealing with a national-scale emission inventory and thus, we only considered emissions coming from national aviation and domestic navigation restricted to fishing boats. For the industry sector, we have used the same systematic approach to deal with the different industries in Lebanon as reported in Waked et al. Intercomparison results are shown in Fig. 2.

For both the air and marine transport sectors, our emission estimates are higher than those of EDGAR by a factor of 9 in the case of $\mathrm{CO}$ and by a factor of 2 for $\mathrm{NO}_{x}$, and lower by a factor of 3 for $\mathrm{SO}_{2}, \mathrm{PM}_{2.5}$ and $\mathrm{PM}_{10}$. As for the energy sector, EDGAR emissions are higher than our estimated values by a factor of 2 for $\mathrm{CO}$ and $\mathrm{NO}_{x}$ and by a factor of 5 for $\mathrm{SO}_{2}$; yet, the EDGAR totals amount to about half our estimate for $\mathrm{PM}_{2.5}$ and $\mathrm{PM}_{1} 0$. This can be attributed to the emission factors used in EDGAR inventory (Janssens-Maenhout et al. 2015) (EDGAR applies a uniform emission factor for all the energy sector in Lebanon). Our methodology, however, uses different emission factors for the different types of fuels used in each subsector as shown in Section ??. For the inventories considered, a large difference in estimated emissions is also found for the industry sector by Waked et al. The basic difference in methodology for the emission factors can be seen in Table 8. Uniform emission factors are used for the industry sector as a whole whereas Waked uses a technology or industry specific emission factor in
Fig. 1 Emissions of the different pollutants by sector (in $\mathrm{Gg}$ )
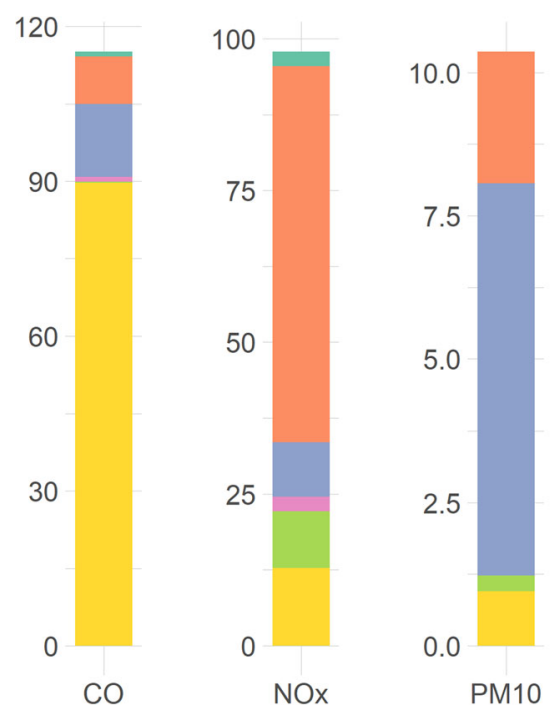

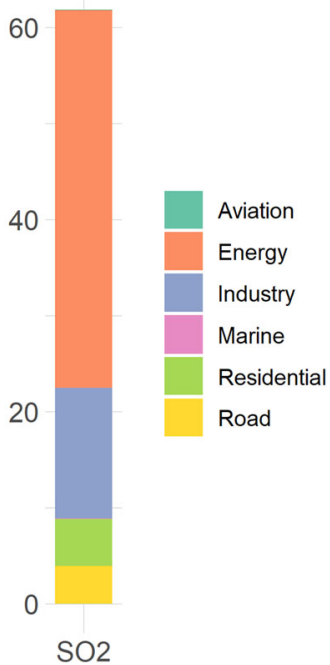



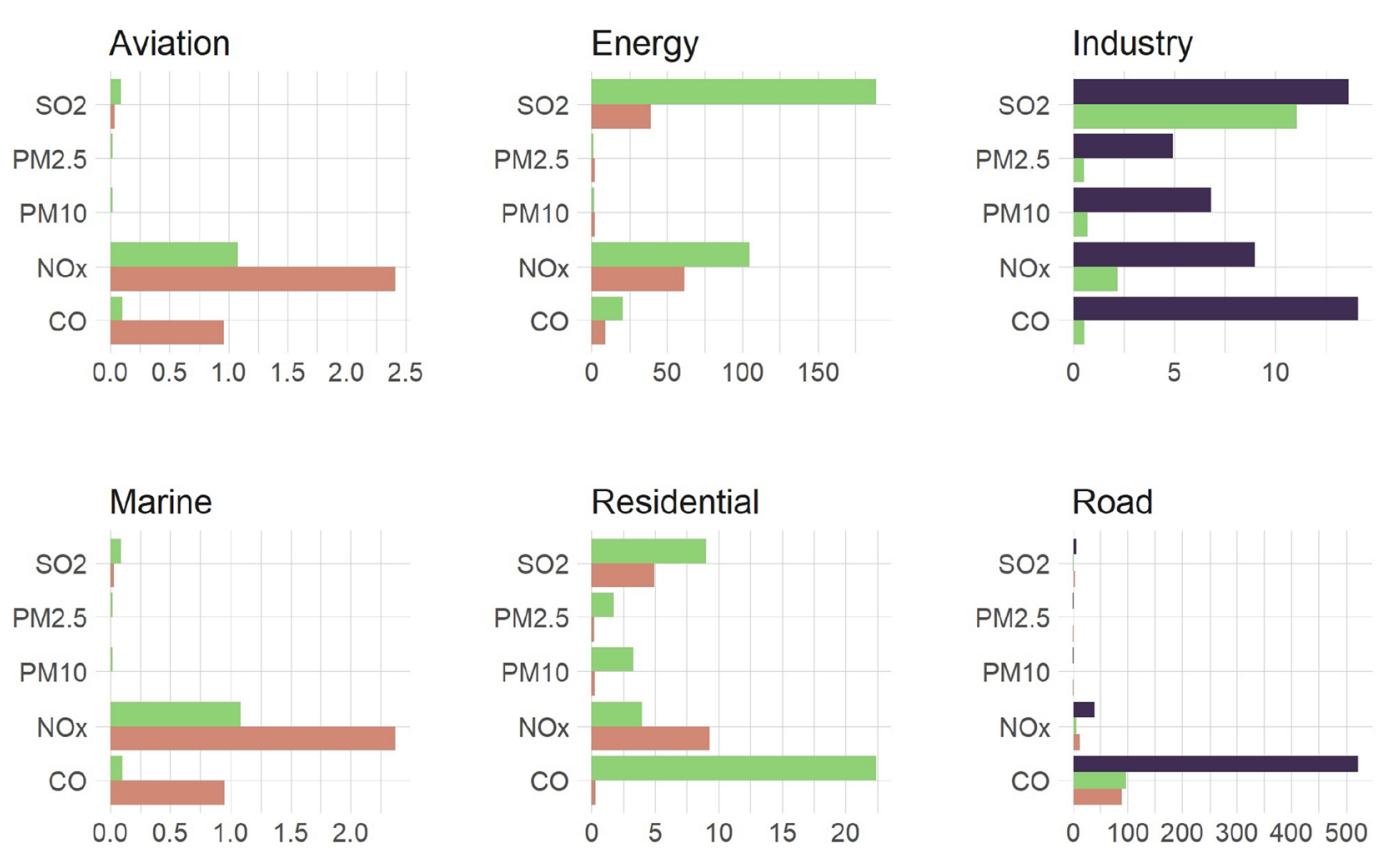

This Study EDGAR

Waked at al. (2012)

Fig. 2 Comparison of emissions (in $\mathrm{Gg}$ ) per pollutants per sector based on our national developed emission inventory

each category of industries present in Lebanon. The same applies for the observed discrepancies at the level of the residential sector as our estimated emissions are about twice those estimated in EDGAR for the case of $\mathrm{NO}_{x}$ only and lower for other studied pollutants as shown in Fig. 2.

The road transport sector emissions obtained are compared with both EDGAR and Waked inventory in Fig. 2. Compared to Waked et al., a significant difference in $\mathrm{CO}$ and $\mathrm{NO}_{x}$ emissions is observed; the estimated emissions in Waked et. al are around 5 times higher. This is attributed to the fact that Waked used the EEA-EMEP emission factors for their estimations (Waked et al. 2012) which implies that all the vehicle fleet is assumed to be from European origin. The emission factors of EEA are usually greater than those for different standards. Our methodology classified the vehicle fleet per origin and used the corresponding emission factors. A comparison of the road transport sector results for all pollutants is depicted in Fig. 3.

Similarly, EDGAR used uniform emission factors throughout the transport sector and its subsectors and for all fuels used as indicated in Table 8. Our national inventory estimations for the road transport sector are within the range of values from EDGAR and Waked inventory for all the studied pollutants, with particulate matter totals closer to Waked et al. estimations. We also note that our total estimated emissions for $\mathrm{NO}_{x}$ and $\mathrm{SO}_{2}$ for all sectors are higher than the estimations of Waked et al. (2012) and lower than EDGAR, while for CO and PMs, we obtain lower annual totals from both other inventories as can be seen in Fig. 4. There is considerable difference between our total estimated $\mathrm{CO}$ emissions and those in Waked et. al. There are indications that the latter may have overestimated the $\mathrm{CO}$ emissions. An air pollution modeling study (Waked et al. 2013) from 2 to 18 July 2011 using WRF-Polyphemus with the emission inventory reported in Waked et. al. as an input reported mean modeled concentration values overpredicted, by about $30 \%$ on average, the observations from a monitoring station located at the University of Saint Joseph (USJ), Beirut. We note however that the data are based on observations from a single monitoring station, and for a small time period (16 days) and may not be representative for the whole country. Based on this study, additional modelling and observation efforts are needed to reach well-founded conclusions on this matter.

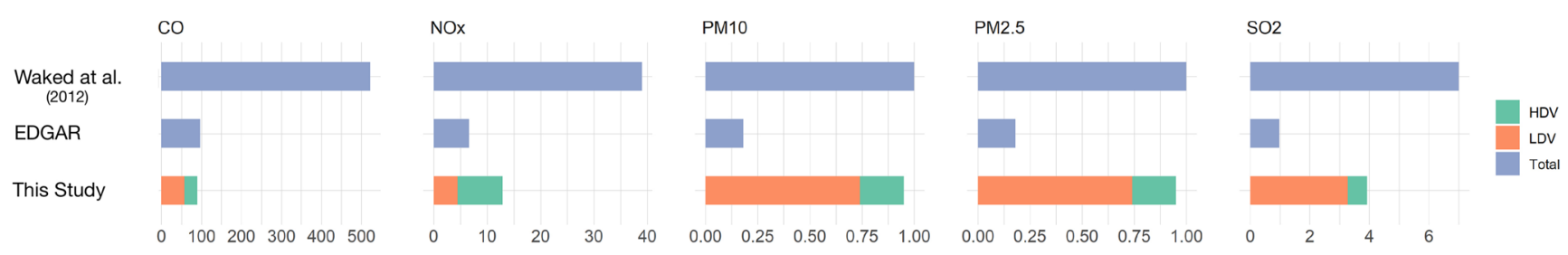

Fig. 3 Comparison of emissions (in $\mathrm{Gg}$ ) of the road transport sector per pollutant 
Fig. 4 Comparison of total emissions $(\mathrm{Gg})$ of all studied sectors between our national inventory, the EDGAR inventory and the Waked et al. (2012) inventory

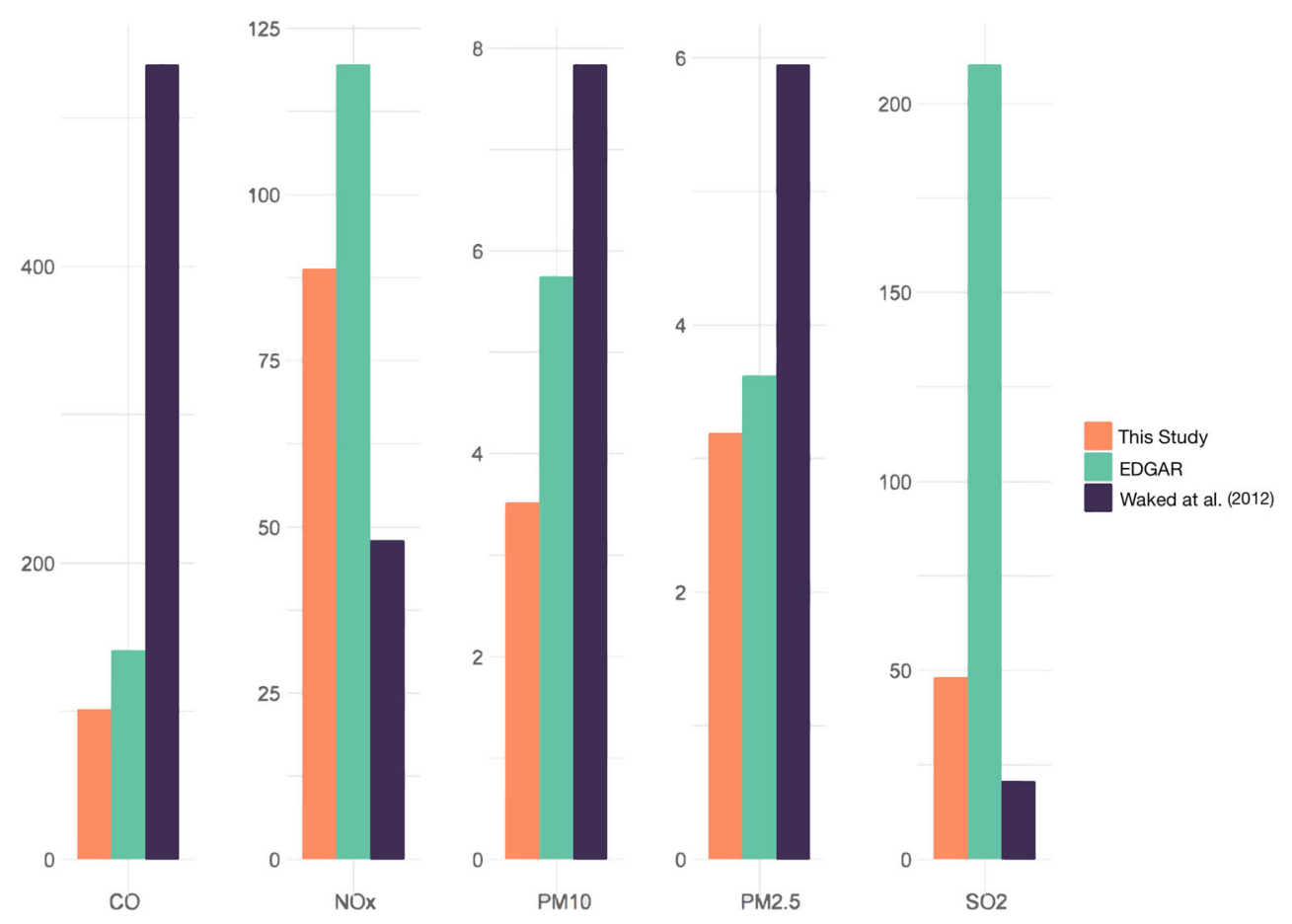

\section{Conclusions and outlook}

We presented an updated national emissions inventory for Lebanon for atmospheric pollutants that are internationally monitored and regulated as relevant to air quality. By exhaustively quantifying detailed multisector, multi-species pollutant emissions, this work serves as a stride to fill the gap by the absence of a clear emission standard and standardized activity datasets in Lebanon. To this end, several methods and input data for the year 2010 were used for the different sectors and subsectors and based on the various types of fuels consumed to refine the accuracy of the estimates.

The updated inventory was compared with EDGAR emission totals for the year 2010 for all sectors and species with several differences emerging. In addition, the road transport subsector was compared with both EDGAR and Waked et al. (2012) inventories where remarkable differences were also apparent. The emissions reported in this paper supersede previously published estimates (Waked et al. 2012) by including emissions for key sources of air pollution in Lebanon that were previously unaccounted for: diesel generators (a major source of energy production and pollution), air and ship transport, and residential space heating and cooking. A large difference in the estimated emissions is also found for the industry sector. This work also improved on previous assumptions (both in waked et al. 2010 and in EDGAR) and used a more detailed analysis of activity data. Major efforts were placed in treating and refining the data, hence revealing how differently that contributed to major discrepancies in the final results of the inventories. The data gaps and discrepancies found highlight the following:

- In Lebanon, the road transport, especially LDVs, and diesel generators subsectors are the major contributors to total emissions of all the studied pollutants.

- For the road transport sector, the estimated CO and $\mathrm{NO}_{x}$ emissions in Waked et al. (2012) are around 5 times higher than our estimates. For the same sector, the estimated EDGAR emissions of PM2.5 and PM10, $\mathrm{NO}_{x}$, and $\mathrm{SO}_{x}$ are around 5, 2, and 5 times lower than our estimates.

- Total estimated emissions for $\mathrm{NO}_{x}$ and $\mathrm{SO}_{2}$ for all sectors are higher than the estimations of Waked et al. (2012) and lower than EDGAR, while CO and PMs annual totals are lower than both other inventories.

- The activity data and their underlying assumptions lead to significant differences in the estimated emissions.

- Emission estimates strongly depend on the methodology and emission factors used, as observed in the estimates for $\mathrm{CO}$ in the industry sector and road, air, and marine transport sectors, $\mathrm{SO}_{2}$ for the energy sector, $\mathrm{NO}_{x}$ for the residential, industry, and marine and road transport sectors, and PMs in the industry and residential sectors.

The observations reveal that emission inventories, especially for data-scarce settings, have a double sensitivity: the activity data and their underlying assumptions lead to significant differences in the estimated emissions on 
the one hand, and, on the other hand, emission estimates vary significantly depending on the methodology used. As such, in the absence of a clear emission standard and standardized activity datasets in Lebanon, future work will focus on further improving the accuracy of the input data required for the estimations. On the other hand, it is of great importance to obtain an inventory taking into account the spatial and temporal distribution of the emissions of the several pollutants in Lebanon.

Supplementary Information The online version contains supplementary material available at https://doi.org/10.1007/s11356-021-17562-8.

Acknowledgements The authors acknowledge the Lebanese Ministries of Environment, Energy and Water, Interior and Municipalities for their support on providing the required data. They also acknowledge the support from the Maroun Semaan Faculty of Engineering and Architecture at the American University of Beirut. The Cyprus Institute acknowledges support from the Project AQ SERVE no. INTEGRATED/0916/0016 which is co-financed by the European Regional Development Fund and the Republic of Cyprus through the Research and Innovation Foundation.

Author contribution Anwar Shami synthesized the methodology, refined emission calculations, compiled emission calculations into a coherent dataset, and produced visualizations.

Elissar Al Aawar calculated of the emissions from the different sectors contributing to the emission inventory, conducted detailed data collection and calculations for the Heavy Duty Vehicles subsection. She also contributed to the organization, writing and editing the manuscript.

Abdelkader Baayoun contributed to writing the Introduction section, in addition to some text in Data and Methods section. He also worked on the methodology, mainly on diesel generators, power plants, and road transport, as well as getting EDGAR emissions for Lebanon from the .nc files using WRF.

Najat Saliba overviewed the calculation of the emission inventory, and co-supervised the work of the contributing students. She also contributed to writing and editing the manuscript.

Jonilda Kushta contributed to the concept of the planned framework and to manuscript writing and editing.

Theodoros Christoudias contributed to the discussion of the results and edited and revised the manuscript.

Issam Lakkis overviewed the whole effort: he co-supervised and co-reviewed the students work, coordinated between the team members, and followed up on the various tasks. He was also responsible for editing, revision, and production of the draft in its submitted from.

Funding This work has been supported by the "Prototype System for a Copernicus $\mathrm{CO} 2$ Service $(\mathrm{CoCO} 2)$ " project that has received funding from the European Union's Horizon 2020 research and innovation programme under Grant Agreement No. 958927. The Cyprus Institute also acknowledges support from the Project AQ SERVE no. INTEGRATED/0916/0016 which is co-financed by the European Regional Development Fund and the Republic of Cyprus through the Research and Innovation Foundation. This work was also partially funded by the Maroun Semaan Faculty of Engineering and Architecture at the American University of Beirut. This publication has been produced within the framework of the EMMECARE project, which has received funding from the European Union's Horizon 2020 Research and Innovation Programme (under grant agreement no. 856612) and the Cyprus Government.
Availability of data and materials Building up the emission inventory discussed in this paper relied on several data sources. These data sources are divided as public sources and private sources. All public sources are cited properly when necessary within the body of the different sections. The relevant titles, hyperlinks and details are stated in correspondence with the journal style. As for the private data sources, these are obtained based on spersonal communication with the ministries of Environment, Energy and Water, Interior and local municipalities. This is pointed out in the text of the different sections when necessary. Data obtained from private communication is not publicly available using a certain hyperlink; however, it will be available from the authors upon reasonable request.

\section{Declarations}

Competing interests The authors declare no competing interests.

Open Access This article is licensed under a Creative Commons Attribution 4.0 International License, which permits use, sharing, adaptation, distribution and reproduction in any medium or format, as long as you give appropriate credit to the original author(s) and the source, provide a link to the Creative Commons licence, and indicate if changes were made. The images or other third party material in this article are included in the article's Creative Commons licence, unless indicated otherwise in a credit line to the material. If material is not included in the article's Creative Commons licence and your intended use is not permitted by statutory regulation or exceeds the permitted use, you will need to obtain permission directly from the copyright holder. To view a copy of this licence, visit http://creativecommons. org/licenses/by/4.0/.

\section{References}

Ipcc guidelines (2006) https://www.ipcc.ch/data, Accessed: April 2019 Ipcc guidelines (2006) volume 2, chapter 3, table 3.6.4

Aviation emissions and the paris agreement (2016) https://www. transportenvironment.org/sites/te/files/publications/Aviation $\% 202030 \% 20$ breifing.pdf

Cas statistical yearbook (2016) http://www.cas.gov.lb, Accessed: April, 2018

EUR (2016) European environment agency, emep/eea air pollutant emission inventory guidebook-energy industries. https:// www.eea.europa.eu/publications/emep-eea-guidebook-2016/ part-b-sectoral-guidance-chapters/1-energy/1-a-combustion/ 1-a-1-energy-industries/view

EUR (2016) European environment agency, emep/eea air pollutant emission inventory guidebook-small combustion. https:// www.eea.europa.eu/publications/emep-eea-guidebook-2016/ part-b-sectoral-guidance-chapters/1-energy/1-a-combustion/ 1-a-4-small-combustion-2016/view

Min (2017) Ministry of interior and municipalities, vehicle fleet

Data and statistics (2019) https://www.iea.org/data-and-statistics, Accessed: December, 2019

Dieselnet (2019) https://www.dieselnet.com, Accessed: December, 2019

Edgar (2019) htap v2. https://edgar.jrc.ec.europa.eu/htap-v2, Accessed: December, 2019

Edgar (2019) joint research centre. emissions database for global atmospheric research. https://edgar.jrc.ec.europa.eu, Accessed: December, 2019

Unf (2019) Emissions from fuels used for international aviation and maritime transport. https://unfcc.int/topics/mitigation/ workstreams/emissions-from-international-transport-bunker-fuels 
Eur (2019) European environment agency, emep/eea air pollutant emission inventory guidebook- industial processes. https:// www.eea.europa.eu/publications/emep-eea-guidebook-2019/ part-b-sectoral-guidance-chapters/2-industrial-processes

Eur (2019) European environment agency, emep/eea air pollutant emission inventory guidebook- international navigation, national navigation, national fishing. https://www.eea.europa.eu/ publications/emep-eea-guidebook-2019/part-b-sectoral-guidancechapters/1-energy/1-a-combustion/1-a-3-d-navigation

Abdallah C, Afif C, El Masri N, Öztürk F, Keleş M, Sartelet K (2018) A first annual assessment of air quality modeling over lebanon using wrf/polyphemus. Atmosph Pollut Res 9(4):643-654

Abdallah C, Sartelet K, Afif C (2016) Influence of boundary conditions and anthropogenic emission inventories on simulated 03 and pm2. 5 concentrations over lebanon. Atmosph Pollut Res 7(6):971-979

Agarwal A, Haritash AK (2014) Air pollution modelling-a review. Int J Adv Technol Eng Sci 2:255-264.

Baayoun A, Itani W, El Helou J, Halabi L, Medlej S, El Malki M, Moukhadder A, Aboujaoude LK, Kabakian V, Mounajed H et al (2019) Emission inventory of key sources of air pollution in lebanon. Atmos Environ 215:116871

Bang HQ, Khue VHN (2019) Air emission inventory, air pollutionmonitoring, quantification and removal of gases and particles. IntechOpen.0

Bergamaschi P, Krol M, Meirink JF, Dentener F, Segers A, van Aardenne J, Monni S, Vermeulen AT, Schmidt M, Ramonet $M$ et al (2010) Inverse modeling of european ch4 emissions 2001-2006. J Geophys Res Atmosph 115(D22)

Bouri E, El Assad J (2016) The lebanese electricity woes: An estimation of the economical costs of power interruptions. Energies 9(8):583

Chaaban FB, Nuwayhid I, Djoundourian S (2001) A study of social and economic implications of mobile sources on air quality in lebanon. Transp Res Part D: Transport Environ 6(5):347-355

Daher N, Saliba NA, Shihadeh AL, Jaafar M, Baalbaki R, Sioutas C (2013) Chemical composition of size-resolved particulate matter at near-freeway and urban background sites in the greater beirut area. Atmosph Environ 80:96-106

Dentener F, Van Weele M, Krol M, Houweling S, Van Velthoven P (2002) Trends and inter-annual variability of methane emissions derived from 1979-1993 global ctm simulations

Fameli K-M, Assimakopoulos VD (2016) The new open flexible emission inventory for greece and the greater athens area (feigregaa): Account of pollutant sources and their importance from 2006 to 2012. Atmos Environ 137:17-37

Finstad A, Haakonsen G, Kvingedal E, Rypdal K (2001) Utslipp til luft av noen miljøgifter i norge-dokumentasjon av metode og resultater (emissions of some hazardous chemicals to air in norway-documentation of methodology and results), report 2001/17. Statistics Norway

Finstad A, Haakonsen G, Rypdal K (2002) Emissions to the air of dioxins in norway: documentation of method and results. Statistics Norway å

Font A, Fuller GW (2016) Did policies to abate atmospheric emissions from traffic have a positive effect in london? Environ Pollut 218:463-474

Georgiou GK, Kushta J, Christoudias T, Proestos Y, Lelieveld J (2019) Air quality modelling over the eastern mediterranean: Seasonal sensitivity to anthropogenic emissions. Atmos Environ: 117119

Georgiou GK, Kushta J, Christoudias T, Proestos Y, Lelieveld J (2020) Air quality modelling over the eastern mediterranean: Seasonal sensitivity to anthropogenic emissions. Atmos Environ 222:117119

Ghadban M, Baayoun A, Lakkis I, Najem S, Saliba NA, Shihadeh A (2020) A novel method to improve temperature forecast in data-scarce urban environments with application to the urban heat island in beirut. Urban Clim 33:100648

Ghanem DA (2018) Energy, the city and everyday life: Living with power outages in post-war lebanon. Energy Res Social Sci 36: $36-43$

Grythe H, Lopez-Aparicio S, Vogt M, Vo Thanh D, Hak C, Halse AK, Hamer P, Sousa Santos G (2019) The metved model: development and evaluation of emissions from residential wood combustion at high spatio-temporal resolution in norway. Atmos Chem Phys 19(15):10217-10237

Guevara M, Tena C, Porquet M, Jorba O, Pérez García-Pando C (2019) Hermesv3, a stand-alone multi-scale atmospheric emission modelling framework-part 1: global and regional module. Geosci Model Dev 12(5):1885-1907

Guevara M, Tena C, Porquet M, Jorba O, Pérez García-Pando C (2020) Hermesv3, a stand-alone multi-scale atmospheric emission modelling framework-part 2: The bottom-up module. Geosci Model Dev 13(3):873-903

Haddad MG, Mansour CJ, Afif C (2018) Future trends and mitigation options for energy consumption and greenhouse gas emissions in a developing country of the middle east region: A case study of lebanon's road transport sector. Environ Model Assessment 23(3):263-276

Hristov AN, Harper M, Meinen R, Day R, Lopes J, Ott T, Venkatesh A, Randles CA (2017) Discrepancies and uncertainties in bottomup gridded inventories of livestock methane emissions for the contiguous united states. Environ Sci Technol 51(23):1366813677

Janssens-Maenhout G, Crippa M, Guizzardi D, Dentener F, Muntean M, Pouliot G, Keating T, Zhang Q, Kurokawa J, Wankmüller R et al (2015) Htap_v2. 2: a mosaic of regional and global emission grid maps for 2008 and 2010 to study hemispheric transport of air pollution. Atmos Chem Phys 15(19):11411-11432

Jin Y, Andersson H, Zhang S (2016) Air pollution control policies in china: a retrospective and prospects. Int J Environ Res Public Health 13(12):1219

Kedia S, Das SK, Islam S, Hazra A, Kumar N (2019) Aerosols impact on the convective and non-convective rain distribution over the indian region: Results from wrf-chem simulation. Atmosph Environ 202:64-74

Kushta J, Georgiou GK, Proestos Y, Christoudias T, Thunis P, Savvides C, Papadopoulos C, Lelieveld J (2019) Evaluation of eu air quality standards through modeling and the fairmode benchmarking methodology. Air Qual Atmosph Health 12(1):7386

Li Y, Chen K (2018) A review of air pollution control policy development and effectiveness in china. Energy Manag Sustain Dev: 1

Liousse C, Keita S, Granier L, Granier C, Elvidge CD, Elguindi N, Law K et al (2019) Flaring emissions in africa: Distribution, evolution and comparison with current inventories. Atmosph Environ 199:423-434

Madrazo J, Clappier A, Belalcazar LC, Cuesta O, Contreras H, Golay F (2018) Screening differences between a local inventory and the emissions database for global atmospheric research (edgar). Sci Total Environ 631:934-941

Ministry of Environment (2015) National greenhouse gas inventory report and mitigation analysis for the energy sector in lebanon. https://www.climamed.eu/wp-content/uploads/files/NationalGreenhouse-Gas-Inventory-Report-Mitigation-Analysis-for-theEnergy-Sector-in-Lebanon.pdf

Ministry of Environment (2015) National greenhouse gas inventory report and mitigation analysis for the transport sector in lebanon. https://www.lb.undp.org/content/lebanon/en/home/library/ environment_energy/national-greenhouse-gas-inventory-reportand-mitigation-analysis.html 
Puliafito SE, Castesana P, Allende D, Ruggeri F, Pinto S, Pascual R, Bolaño Ortiz T, Fernandez RP (2017) High-resolution atmospheric emission inventory of the argentine enery sector. In: EGU General Assembly Conference Abstracts, vol 19, p 5564

Reichle LJ, Cook R, Yanca CA, Sonntag DB (2015) Development of organic gas exhaust speciation profiles for nonroad spark-ignition and compression-ignition engines and equipment. J Air Waste Manag Assoc 65(10):1185-1193

Salameh T, Sauvage S, Afif C, Borbon A, Locoge N (2016) Source apportionment vs. emission inventories of non-methane hydrocarbons (nmhc) in an urban area of the middle east: local and global perspectives. Atmos Chem Phys 16(5):3595-3607

Shihadeh A, Al Helou M, Saliba N, Jaber S, Alaeddine N, Ibrahim E (2018) Effect of distributed electric power generation on household exposure to airborne carcinogens in beirut. Climate Change and Environment in the Arab World

UNECE RN (2011) Regulation no 83 of the economic commission for europe of the united nations (un/ece) - uniform provisions concerning the approval of vehicles with regard to the emission of pollutants according to engine fuel requirements

UNFCCC (2011) Second national communication to the unfecc. ministry of environment, beirut

Upadhyay A, Dey S, Goyal P (2019) A comparative assessment of regional representativeness of edgar and eclipse emission inventories for air quality studies in india. Atmos Environ:117182 van Amstel A, Olivier J, Janssen L (1999) Analysis of differences between national inventories and an emissions database for global atmospheric research (edgar). Environ Sci Policy 2(3):275-293

Waked A, Afif C, Seigneur C (2012) An atmospheric emission inventory of anthropogenic and biogenic sources for lebanon. Atmosph Environ 50:88-96

Waked A, Seigneur C, Couvidat F, Kim Y, Sartelet K, Afif C, Borbon A, Formenti P, Sauvage S (2013) Modeling air pollution in lebanon: evaluation at a suburban site in beirut during summer. Atmos Chem Phys 13(12):5873-5886

Wang SX, Zhao B, Cai SY, Klimont Z, Nielsen CP, Morikawa T, Woo JH, Kim Y, Fu X, Xu JY et al (2014) Emission trends and mitigation options for air pollutants in east asia. Atmos Chem Phys 14(13):6571-6603

Yan D, Liu T, Dong W, Liao X, Luo S, Wu K, Zhu X, Zheng Z, Wen $X$ (2019) Integrating remote sensing data with wrf model for improved 2-m temperature and humidity simulations in china. Dyn Atmosph Oceans: 101127

Zhao J, Guo Z-H, Su Z-Y, Zhao Z-Y, Xiao X, Liu F (2016) An improved multi-step forecasting model based on wrf ensembles and creative fuzzy systems for wind speed. Appl Energy 162:808826

Publisher's note Springer Nature remains neutral with regard to jurisdictional claims in published maps and institutional affiliations.

\title{
Affiliations
}

\author{
Anwar Al Shami ${ }^{1}$ - Elissar Al Aawar ${ }^{2}$ Abdelkader Baayoun ${ }^{2}$ - Najat A. Saliba ${ }^{3}$ - Jonilda Kushta ${ }^{4}$ \\ Theodoros Christoudias $^{4}$. Issam Lakkis ${ }^{2}$ (D)
}

\author{
Anwar Al Shami \\ Elissar Al Aawar \\ eta10@mail.aub.edu \\ Abdelkader Baayoun \\ ahb25@mail.aub.edu
}

anwar.alshami@alesopi.com

Najat A. Saliba

ns30@aub.edu.lb

Jonilda Kushta

j.kushta@cyi.ac.cy

Theodoros Christoudias

t.christoudias@cyi.ac.cy

1 ALESOPI Consulting, 15 Chemin de Coton, 26120

Chateaudouble, France

2 Department of Mechanical Engineering, Maroun Semaan

Faculty of Engineering and Architecture, American

University of Beirut, Beirut, Lebanon

3 Department of Chemistry, Faculty of Arts and Sciences, American University of Beirut, Beirut, Lebanon

4 Environmental Predictions Department, Climate and Atmosphere Research Center, The Cyprus Institute, Nicosia, Cyprus 